\title{
Corrosion Characteristics of Laser-Engineered Net Shaping Additively-Manufactured 316L Stainless Steel
}

\author{
JAMIE A. STULL, ${ }^{1,3}$ MARY ANN HILL, ${ }^{1}$ THOMAS J. LIENERT, ${ }^{1}$ \\ JUSTIN TOKASH, ${ }^{2}$ KEVIN R. BOHN, ${ }^{1}$ and DANIEL E. HOOKS ${ }^{1}$
}

1.-Los Alamos National Laboratory, Los Alamos, NM 87545, USA. 2.-Y-12 National Security Complex, Oak Ridge, TN 37830, USA. 3.—e-mail: jamie.stull@lanl.gov

\begin{abstract}
The single-loop electrochemical potentiokinetic reactivation (EPR) test was used to quantify the degree of sensitization for 316L stainless steel (SS) produced by laser-engineered net shaping $\left(\mathrm{LENS}^{\circledR}\right)$ additive manufacturing $(\mathrm{AM})$. EPR tests were also used to monitor how the sensitivity of the as-deposited and heat-treated AM material compared to wrought 316L SS. A solution-annealing heat treatment that recrystallized the material was also applied to AM-316L SS. The EPR tests showed that as-deposited AM-316L SS displayed low levels of sensitization. Heat-treated AM-316L SS demonstrated some improvements in resistance to corrosion, but overall did not perform as well as wrought 316L material. Optical micrographs of the AM-316L SS samples collected after conducting the EPR tests also showed localization in the asdeposited AM-316L SS material; however, these features were reduced after heat treatment, suggesting greater resistance to corrosion.
\end{abstract}

\section{INTRODUCTION}

The development of additive manufacturing (AM) has revolutionized manufacturing processes for a wide variety of materials, including polymers, composites, metals, and ceramics. ${ }^{1-10}$ AM employs a layer-by-layer approach capable of producing complex part designs in a time- and cost- effective manner, which notably can achieve shapes that are difficult or impossible to make by traditional methods. AM products must retain or exceed the desired material properties of products manufactured using traditional manufacturing methods. For metals, traditional manufacturing techniques are typically based on cast and/or wrought methods. These materials are typically machined or welded to a final shape. AM of metals can be achieved using a variety of processes, including electron beam melting, direct energy deposition with laser, and powder bed fusion-laser (PBF-L) AM. ${ }^{8,11-17}$

A wide variety of stainless steels (SSs) exist that can be processed using AM. Two common austenitic SSs that are processed using AM and traditional manufacturing methods are $304 \mathrm{~L}$ SS $(18 \mathrm{Cr}-8 \mathrm{Ni}-\mathrm{L}$ C) and 316L SS (19Cr-9Ni-3Mo-L C). The "L" denotes that these grades of SS are low in carbon content $(<0.03 \%)$, which improves the corrosion properties. When these SSs are exposed to elevated temperatures $\left(450-850^{\circ} \mathrm{C}\right)$ due to welding, heat treatment, fabrication, or service conditions, chromium-rich carbides will form along the grain boundaries. ${ }^{18}$ Precipitation of these carbides results in chromium-depleted regions adjacent to the carbides on the grain boundaries. Carbide precipitation (and subsequent chromium depletion) can give rise to the phenomenon known as sensitization, which can cause corrosion depending on the environmental conditions causing the attack. ${ }^{19}$ These regions of chromium depletion are anodic with respect to the matrix, which creates a galvanic potential and facilitates corrosion locally. ${ }^{20-22}$

Welding and AM processes can also cause local heating and subsequent cooling, which create residual stresses that can impact the corrosion resistance, fatigue wear, and induce stress corrosion cracking. ${ }^{16,23-25}$ In certain corrosive environments, such as those used in electrochemical potentiokinetic reactivation (EPR) tests, the material can become sensitized when the chromium content is less than $12-13 \%$ in the chromium-depleted regions. Austenitic SSs, such as 316 (18Cr-12Ni-2Mo) and $304(18 \mathrm{Cr}-8 \mathrm{Ni})$, are susceptible to corrosion via intergranular corrosion (IGC) and intergranular stress corrosion cracking (IGSCC) due to 
sensitization. One method of improving the IGC resistance of SS is to decrease the carbon content. ${ }^{19,25} 316 \mathrm{~L}$ SS is a common austenitic SS with alloy chemistries including low carbon content $(<0.03 \%)$ and molybdenum $(\sim 2-3 \%)$.

Due to the nature of processing AM components, the resulting microstructure can exhibit characteristics that are analogous to typical cast or welded material with a solidification texture and anisotropic mechanical properties, in contrast to wrought SSs that have been formed by rolling, forging or extrusion, which show different microstructures. ${ }^{16,26,27}$ There have been few reports on the corrosion properties of AM 316L SS. In general, previous work on $316 \mathrm{~L}$ produced by AM was found to exhibit increased levels of sensitization compared to wrought and weld deposits using plasma-transferred arc welding (PTAW). ${ }^{16,40}$ Subsequent solution annealing of laser rapid manufacturing (LRM) 316L SS was found to decrease the degree of sensitization and heal chromium depletion to some extent. $^{16}$

Alternative fabrication methods such as powder metallurgy (PM) processing have also been used to compact 316L SS powders to form solid compacts. In studies by Garcia et al., the corrosion properties of wrought and PM 316L SS were compared. ${ }^{28,29}$ PM 316L SS discs were prepared by sintering green compacts. EPR tests comparing the corrosion properties of the two material types showed that PM 316L SS samples exhibited a higher degree of sensitization, or lower corrosion resistance. Microscopy studies on PM 316L SS revealed microstructures with higher exposed surface areas compared to wrought $316 \mathrm{~L}$ SS, which contributed to the reduced corrosion resistance of PM 316L SS.

The present study focuses on the corrosion properties of 316L SS manufactured using laserengineered net shaping (LENS ${ }^{\circledR}$ ) AM determined by EPR testing. ${ }^{30}$ The EPR test is a non-destructive technique that was developed by Novak et al. and Clarke et al. ${ }^{31-33}$ This technique was later standardized by ASTM to quantify the degree of sensitization in AISI types 304 and 304L SS, but has also been used on a number of different SSs, including $316 \mathrm{~L} \cdot{ }^{34,35}$ In order to measure the corrosion resistance properties of AM-316L SS and wrought 316L SS, EPR tests were performed to determine the degree of sensitization for the two different materials. The microstructure of AM316L SS was characterized before and after heat treatment using light optical microscopy (LOM). The composition, microstructure, and mechanical behavior of these materials has previously been tested. ${ }^{14,29,36-38}$ Here, we extend this work by addressing the corrosion properties of the materials.

\section{MATERIALS AND METHODS}

This work was conducted on wrought 316L SS material that was sourced in 12.5-mm-thick plate form. The AM-316L SS was produced using LENS AM. The stock powder used for AM was a gasatomized powder purchased from Carpenter Powder Products (Bridgewater, PA, USA). Table I provides the analyzed chemical composition of the as-received powder used in the LENS build and the wrought $316 \mathrm{~L}$ material. The chemical composition of the materials was provided by the manufacturer using optical emission spectroscopy and inductively coupled plasma-mass spectrometry. A third party was also used to determine the chemical composition of the AM powder. The 316L SS material specifications have been included from Ref. 39. The particle size distribution of the powder used for the LENS build was measured to be $53-180 \mu \mathrm{m}$. An OPTOMEC (Albuquerque, NM, USA) LENS MR-7 laser AM system was used to produce the AM-316L SS samples. The layer height of the AM-316L SS LENS build was 0.012 inches $(0.03 \mathrm{~mm})$ per layer. Further details on the LENS configuration and build specifications have been described by Gray et al. and Morrow et al. ${ }^{36,37}$

The heat treatment applied to the AM-316L SS material was performed at $1060^{\circ} \mathrm{C}$ for $1 \mathrm{~h}$ under vacuum with subsequent rapid quenching in an oil bath to suppress the precipitation of any carbides and intermetallics. The heat treatment was chosen to homogenize composition of the AM-316L SS. From here on, the non-heat-treated materials (i.e., as-deposited) are referred to as AM-316L NHT SS, and 316L NHT (wrought), and the heat-treated material is referred to as AM-316L HT SS.

Single loop (SL) EPR experiments were performed following ASTM G108-94 to evaluate susceptibility to intergranular or non-uniform corrosion. ${ }^{40}$ The size of the $316 \mathrm{~L}$ wrought sample used in the EPR tests was $1 \mathrm{~cm}^{2}$ and the AM-316L SS samples were all $0.8 \mathrm{~cm}^{2}$. The samples were mounted in Lucite, and standard metallographic techniques were employed to polish the sample used for EPR tests to a 1- $\mu \mathrm{m}$ diamond finish. A fresh solution of $0.5 \mathrm{M}$ sulfuric acid $\left(\mathrm{H}_{2} \mathrm{SO}_{4}\right)$ and $0.01 \mathrm{M}$ potassium thiocyanate (KSCN) was used for each test. The EPR experiments were performed at a temperature $30 \pm 1^{\circ} \mathrm{C}$ using a Gamry Reference 3000 or a Gamry Reference $600+$ potentiostat, a platinum counter electrode, and a saturated calomel reference electrode. The EPR experiments were repeated at least twice on each sample to ensure reproducibility of the results.

All LOM images were collected using a Zeiss Axio Imager M2m optical microscope with varied magnification. 


\section{RESULTS}

Micrographs at two different magnifications of asdeposited (AM-316L NHT SS) and the heat-treated (AM-316L HT SS) are shown in Fig. 1. Micrographs of AM-316L NHT SS (Fig. 1a) reveal that the microstructure of the AM material exhibits a solidification structure with microsegregation, resulting in a network of melt pools. The as-deposited AM316L NHT SS solidified with a primary ferrite (BCC structure) solidification structure (dark phase), which is more clearly observed in the high-resolution Fig. 1b. This ferrite structure persists at the dendrite or cell core and includes more chromium and molybdenum than the interdendritic or intercellular regions with an austenitic (FCC) crystal structure. ${ }^{28}$ The cell cores are rich in chromium and molybdenum with reduced concentrations of nickel, which results in a galvanic difference relative to the interdendritic regions. ${ }^{21,22}$ There are also macrosegregation patterns associated with each layer where the changing solidification gradient and solidification growth rate vary spatially in each layer as the laser heat source moves. ${ }^{25}$ The extent of the microsegregation, fraction of ferrite and the cell size vary spatially in each layer as a function of the fluctuating solidification gradient and growth rate. Figure 1c and $d$ shows the changes to the asdeposited Am-316L NHT SSs after heat treatment. Micrographs of AM-316L HT SS indicate that the

Table I. Chemical composition of the 316L AM powder, wrought 316L SS, and 316L specifications

\begin{tabular}{|c|c|c|c|c|c|c|c|c|c|c|}
\hline \multirow[b]{2}{*}{ Material } & \multicolumn{10}{|c|}{ Composition (wt.\%) } \\
\hline & $\mathbf{C}$ & $\mathbf{C r}$ & $\mathbf{C u}$ & Mn & Mo & $\mathbf{N}$ & Ni & Si & $\mathbf{P}$ & $\mathbf{S}$ \\
\hline $\begin{array}{l}\text { AM-316L } \\
\text { powder }\end{array}$ & 0.02 & 20.7 & 0.19 & 1.32 & 2.45 & 0.09 & 11.4 & 0.50 & 0.02 & 0.01 \\
\hline $\begin{array}{l}316 \mathrm{~L} \\
\text { wrought }\end{array}$ & 0.022 & 16.16 & 0.39 & 1.70 & 2.08 & 0.063 & 10.03 & 0.029 & 0.0004 & 0.040 \\
\hline $316 \mathrm{~L}$ spec $^{39}$ & $\begin{array}{c}0.030 \\
\max \end{array}$ & $\begin{array}{c}16.0- \\
18.0\end{array}$ & - & $\begin{array}{l}2.00 \\
\max \end{array}$ & $\begin{array}{c}2.00- \\
3.00\end{array}$ & $\begin{array}{l}0.10 \\
\max \end{array}$ & $\begin{array}{c}10.0- \\
14.0\end{array}$ & $\begin{array}{l}1.00 \\
\max \end{array}$ & $\begin{array}{l}0.045 \\
\max \end{array}$ & $\begin{array}{c}0.030 \\
\max \end{array}$ \\
\hline
\end{tabular}
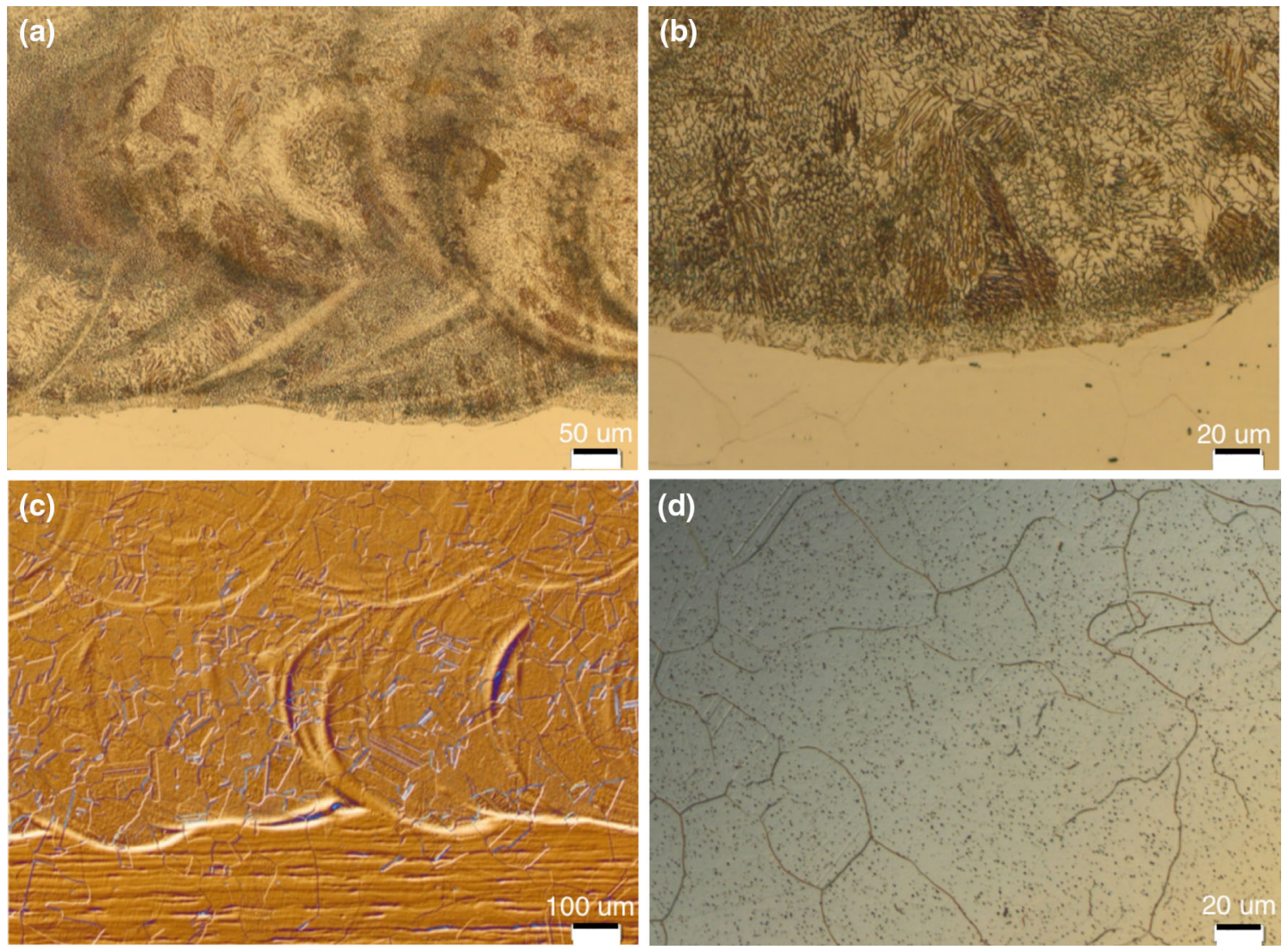

Fig. 1. Optical micrographs of the (a, b) AM-316L NHT SS material and (c, d) AM-316L HT SS material. 


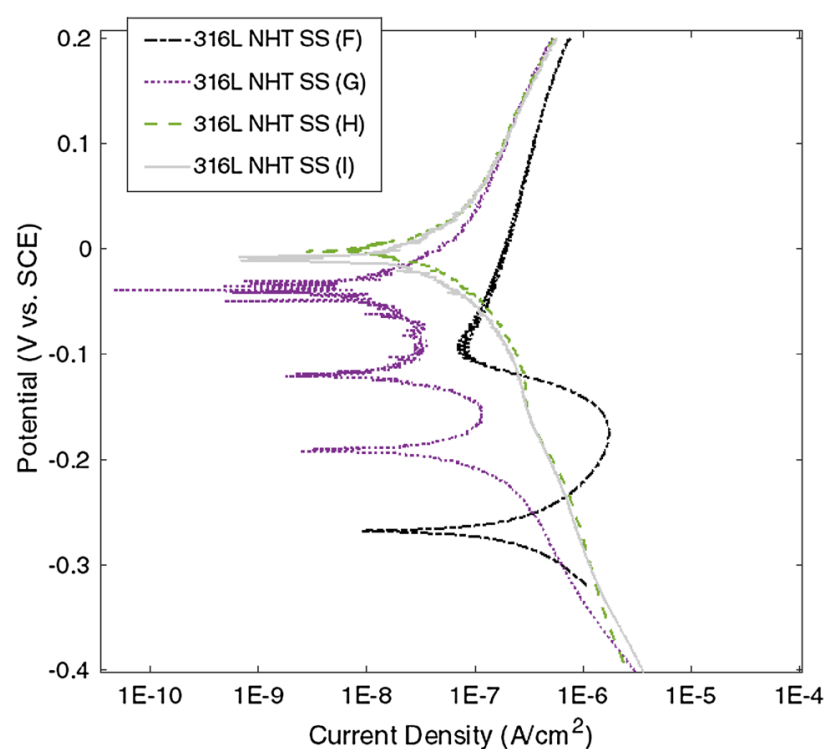

Fig. 2. The potential versus current density curves collected during the SL EPR tests on wrought SS. 316L NHT SS refers to as-received wrought SS. Traces $F-l$ show the repeated EPR tests for asreceived wrought SS and correspond to the data in Table II.

ferrite dissolved and subsequently recrystallized removing the majority of the macrosegregation. Figure 1d shows that the microstructure of the heat-treated samples contained a small volume fraction of a second phase that is spherical in shape and $0.3-1 \mu \mathrm{m}$ in diameter. Further discussion of the characterization of the secondary phase and the grain structure has been detailed by Morrow et al. ${ }^{37}$ The network of melt pools observed in Fig. 1c for the AM 316L HT SS material after oxalic etching suggests that some segregation remains after heat treatment.

The degree of sensitization induced by IGC and IGSCC on the AM-316L SS and the as-received wrought 316L SS was measured using the SL EPR test. A potentiodynamic sweep was applied to the SS samples from the passive to the active region of the electrochemical potentials. This procedure is referred to as reactivation. Figure 2 shows the EPR results of the the as-received wrought $316 \mathrm{~L}$ NHT SS. Figure 3 presents EPR test results performed on the as-deposited AM-316L NHT SS and the AM-316L SS samples that were exposed to heat treatment (AM-316L HT SS). The suffix is used to distinguish repeated EPR tests. The charge density can be calculated by integrating the area under the reactivation curve and normalizing based on sample size. The charge density under the reactivation peak provides information on the quantity of electric charge passing through the surface exposed to the test solution. For the SL EPR test, the charge density is typically normalized by the grain size of the material; however, since AM-316L has an equiaxed grain structure due to the processing of the material, it is difficult to measure a

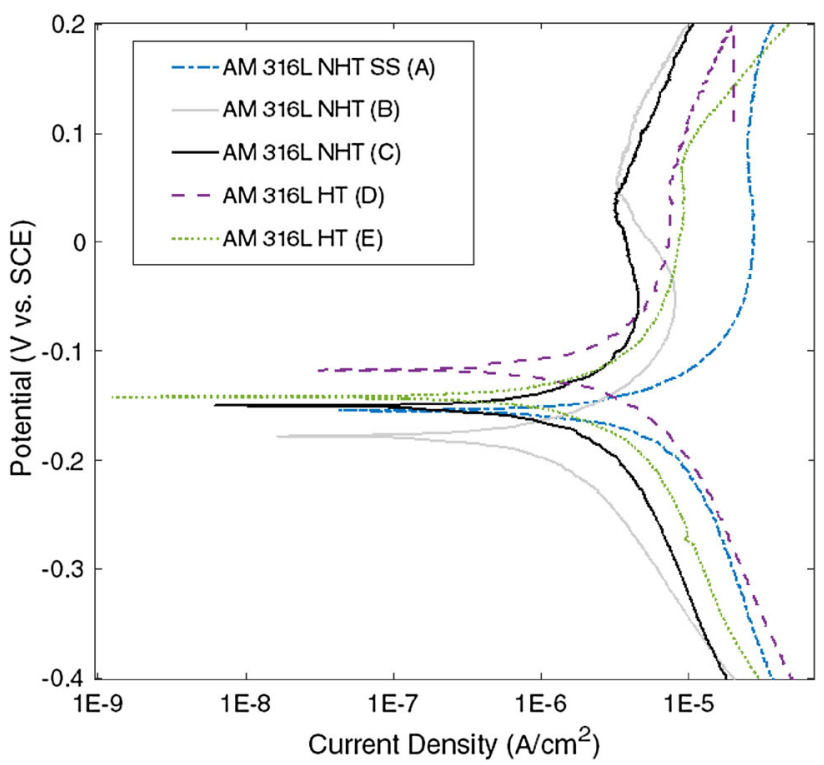

Fig. 3. The potential versus current density curves collected during the SL EPR tests on the as-deposited (AM-316L NHT SS) and heattreated AM-316L SS (AM-316L HT SS). Traces $A-C$ are repeats of the EPR tests for as-deposited AM-316L SS, and traces $D$, and $E$ show the repeated EPR tests for heat-treated AM-316L SS. The data for each trace can be seen in Table II.

representative grain size. Therefore, only the reactivation charge densities for each sample tested have been reported in Table II.

The reactivation curves for the as-received wrought 316L NHT and AM-316L SS materials are shown in Figs. 3 and 4, respectively. The average charge density for the wrought 316L NHT samples was $0.38 \pm 0.27 \mathrm{mC} / \mathrm{cm}^{2}$, which is lower than that measured for the AM-316L SS samples. Some reactivation was observed in the as-deposited AM-316L NHT SS, which has an average charge density $1.64 \pm 1.76 \mathrm{mC} / \mathrm{cm}^{2}$. However, there was significant variation in the EPR results for this sample between each of the EPR tests, as seen in Fig. 3 and Table II. After the annealing treatment, a small decrease in the charge density was measured. The average charge density for the heattreated AM-316 HT SS was $1.03 \pm 0.06 \mathrm{mC} / \mathrm{cm}^{2}$. These results suggest that the annealing heattreatment decreases the sensitization of the AM$316 \mathrm{~L} \mathrm{SS}$, and therefore may reduce the susceptibility to IGC and IGSCC. For reference, unpublished results of sensitized wrought $316 \mathrm{~L}$ SS reveal a charge density of $110.1 \mathrm{mC} / \mathrm{cm}^{2}$. SL EPR results on similar SSs that are sensitized due to processing report much higher charge densities. ${ }^{41,42}$ During processes such as welding, chromium carbides can precipitate at the grain boundaries and contribute to sensitization; however, similar heat treatments have been shown to heal the sensitization in the material. ${ }^{25}$ Although sensitization is observed in AM-316L SS, even with annealing, the results described here are consistent with relatively low levels of precipitated chromium carbides. 
Table II. Integrated charge from the area under the reactivation curve in the EPR tests

\begin{tabular}{|c|c|c|c|}
\hline Material & Sample & $E_{\text {corr }}($ corrosion potential, $\mathbf{m V})$ & Reactivation charge density $\left(\mathrm{mC} / \mathrm{cm}^{2}\right)$ \\
\hline \multirow{3}{*}{ AM-316L NHT SS } & A & -0.154 & 3.66 \\
\hline & $\mathrm{B}$ & -0.177 & 0.84 \\
\hline & $\mathrm{C}$ & -0.099 & 0.42 \\
\hline \multirow[t]{2}{*}{ AM-316L HT SS } & $\mathrm{D}$ & -0.110 & 0.99 \\
\hline & $\mathrm{E}$ & -0.142 & 1.08 \\
\hline \multirow[t]{4}{*}{ Wrought 316L NHT SS } & $\mathrm{F}$ & -0.268 & 0.78 \\
\hline & $\mathrm{G}$ & -0.192 & 0.26 \\
\hline & $\mathrm{H}$ & -0.00284 & 0.23 \\
\hline & $\mathrm{I}$ & -0.00790 & 0.25 \\
\hline
\end{tabular}
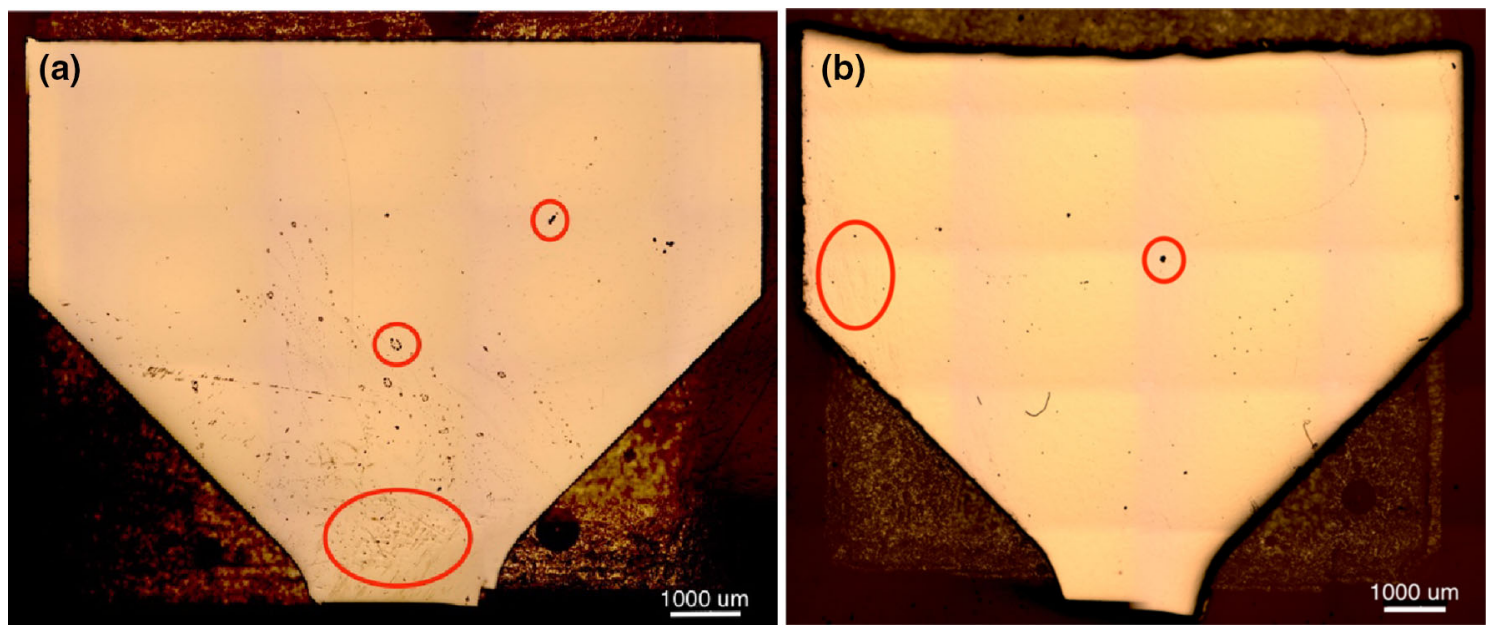

Fig. 4. Micrographs of the 316L SS samples post-EPR tests: (a) AM-316L NHT SS; (b) AM-316L HT SS.

Furthermore, in previous studies on this AM-316L material, no evidence for chromium carbides in the solidified structure was observed. ${ }^{37}$

During the potentiodynamic sweep, reactivation of the sample results from the preferential passive film breakdown at the chromium-depleted regions. The majority of the samples tested had a defined reactivation region in which the area could be integrated. In some of the 316L NHT SS samples, a true reactivation curve was not observed, or was small. This suggests that the material was not sensitized and the passive film remained intact. This observation is typical for annealed wrought 316L SS, since appropriate heat treatments are performed to remove sensitization. ${ }^{43-46}$ If the sensitization conditions are not met, no reactivation curve will be observed during EPR testing. ${ }^{47,48}$ Additionally, the presence of molybdenum will enhance the passivity of $316 / 316 \mathrm{~L}$ type $\mathrm{SS} .^{47}$

Figure $4 \mathrm{a}$ shows a micrograph image of the asdeposited AM-316L NHT SS after EPR testing, exhibiting localization or pitting of the material. The presence of localization features is consistent with the build features of AM 316L SS. The localization is present as both isolated corrosion pits, clusters, and elongated corrosion pits, highlighted by red circles in Fig. 4. The micrograph of AM-316L HT SS in Fig. 4b, however, revealed significantly less localization, which is consistent with the EPR results in this work. The observed localization may be related to the microsegregation seen previously in the micrographs in Fig. 1a and b, which shows that the AM-316L NHT SS material was not uniform after solidification. The segregation of chromium and molybdenum from the nickel will produce a galvanic difference within the material, which has been well established for castings and arc welds. ${ }^{21,22}$ This galvanic difference can produce nucleation sites for corrosion. Even after heat treatment of AM-316L SS, a heterogeneous structure containing melt pools was still observed in the AM-316L HT SS (Fig. 1d), indicating that some segregation still remains after heat treatment. This observation may explain the limited localization and pitting observed in Fig. 4b for AM-316L HT SS.

\section{DISCUSSION}

Welded and AM metals are metallurgically inhomogenous compared to wrought base metal. Slower cooling during the manufacturing of AM SS may promote sensitization due to the precipitation of 
chromium-rich carbides and associated chromium depletion near the grain boundaries. Our results for AM-316L HT SS, which describe slightly elevated corrosion levels compared with wrought 316L SS, are similar to previous work on 316L SS produced using AM fabrication methods. Trelewicz et al. showed that 316L fabricated using PBF-L had reduced corrosion resistance compared to wrought $316 \mathrm{~L}$ SS that had been heat-treated, which is unsurprising as the heat treatment applied to the wrought 316L SS in this work is known to decrease the degree of sensitization in wrought $316 \mathrm{~L}$ SS. ${ }^{40,43-46}$ Therefore, since the PBF-L-produced $316 \mathrm{~L}$ SS was not heat treated, a direct comparison between the two materials is difficult, especially since as-deposited AM and welded materials are known to include residual stresses that can deteriorate corrosion resistance. ${ }^{16,23-25}$

SS produced by PM or subject to welding methods is also recognized for having an increased degree of sensitization, due to increased porosity and localized heating, compared with wrought material. ${ }^{16,23-25,49,50}$ In PM SS, the degree of sensitization is increased due to the porosity, which behaves similarly to pre-existing crevices, resulting in an increased corrosion rate. ${ }^{5,52}$ The LENS AM$316 \mathrm{~L}$ in this work appears to be fully dense; no pores were apparent at the provided magnifications for the optical images in these experiments. Transmission electron microscopy and optical images collected by Morrow et al. also did not reveal any pores in the material. ${ }^{37}$ The lack of pores in the AM-316L SS may help explain the low levels of sensitization. EPR studies by Ganesh et al. on LRM and PTAW 316L SS also found that solution annealing showed modest improvements in the pitting corrosion resistance of LRM-316L SS. ${ }^{16}$ However, overall, LRM and PTAW 316L exhibited lower resistance to pitting corrosion in contrast to wrought-type $316 \mathrm{~L}$ SS. ${ }^{16}$ Even with annealing heat treatments, it appears that AM-316L SSs do not perform as well as wrought $316 \mathrm{~L}$ SSs that have been exposed to similar annealing heat treatments and similar corrosive environments. ${ }^{43-46}$ The extent of corrosion in a SS will depend on a number of factors, including the corrosive environment, degree of sensitization, grain structure and size, passive film stability, alloy element segregation, precipitation of carbides and intermetallics, and composition of the SS. ${ }^{53}$ Because of these factors, it can be difficult to compare the degree of sensitization and corrosion susceptibility for different materials that have different solidification morphology and may be tested in different corrosive environments.

As mentioned previously, we did not observe any precipitated chromium carbides in this or previous work, which could be related to the relatively low levels of sensitization that were measured by the EPR tests. ${ }^{37,41,42}$ The low-level sensitization that was observed in AM-316L SS could originate from the austenite phase that was seen in the micrographs. The austenite phase in SSs typically contains less chromium than the ferritic matrix, and subsequently, this phase is preferentially attacked in electrochemical corrosion tests. ${ }^{19}$ It is also possible that the precipitate morphologies of the carbides that are present are very small and difficult to resolve using conventional metallographic techniques. ${ }^{41}$ Combined, these inconsistences in the microstructure and uneven precipitation of chromium-rich carbides can lead to a variety of corrosion mechanisms that will degrade the passive film and enhance the corrosion rate in corrosive environments.

\section{CONCLUSION}

The corrosion properties of AM-316L SS produced by LENS ${ }^{\circledR}$ AM fabrication have been compared with wrought $316 \mathrm{~L}$ SS. The annealing heat-treatment applied to AM-316L SS was intended to homogenize the material and redissolve any chromium-rich carbides that precipitated during the AM process. The results of the SL EPR tests, measuring the sensitivity of the as-deposited AM-316L NHT SS suggested that the material had an increased degree of sensitization compared to as-received wrought $316 \mathrm{~L}$ SS, in equivalent corrosive environments. Even after heat treatment, AM-316L SS was still susceptible to reactivation. These results agree with previous work on 316L SS produced using PBF-L AM, LRM AM, and PM. Overall, it is difficult to quantify the degree of sensitization in $316 \mathrm{~L}$ SS fabricated by different AM techniques due to differences in porosity, heat treatments, grain sizes, and process histories of the materials. At best, it appears that AM-316L SS exhibited corrosion resistance similar to welded-type 316L SS materials, which apparently contained enough chromium carbide precipitation to cause sensitization in the environment tested. AM 316L SSs evidently exhibit slightly lower corrosion resistance compared with wroughttype 316L SSs. These results demonstrate that more work needs to be performed to fully characterize SSs produced by AM methods in order to allow direct comparisons between different methods of fabrication, which can have variations in the feedstock material, AM fabrication method, and instrument process settings. The subsequent microstructure can have significant effects on materials performance, as we have shown here in the corrosion properties of AM-316L SS.

\section{ACKNOWLEDGEMENTS}

Los Alamos National Laboratory is operated by Los Alamos National Security, LLC, for the National Nuclear Security Administration of the U.S. Department of Energy under Contract DE-AC5206NA25396. We also thank Bob Forsyth and the Sigma Characterization and Special Projects team for helping with some of the microscopy and sample preparation. 


\section{REFERENCES}

1. G.B. Compton and J.A. Lewis, Adv. Mater. 26, 5930 (2014).

2. Z.C. Eckel, C. Zhou, J.H. Martin, A.J. Jacobsen, W.B. Carter, and T.A. Schaedler, Science 351, 58 (2016).

3. R.L. Truby and J.A. Lewis, Nature 540, 371 (2016).

4. S.C. Ligon, R. Liska, J. Stampfl, M. Gurr, and R. Mulhaupt, Chem. Rev. 117, 10212 (2017).

5. P. Parandoush and D. Lin, Compos. Struct. 182, 36 (2017).

6. H.L. Tekinalp, V. Kunc, G.M. Velez-Garcia, C.E. Duty, L.J. Love, A.K. Naskar, C.A. Blue, and S. Ozcan, Compos. Sci. Technol. 105, 144 (2014).

7. F.E. William, J. Mater. Eng. Perform. 23, 1917 (2014).

8. D.D. Gu, W. Meiners, K. Wissenbach, and R. Proprawe, Int. Mater. Rev. 57, 133 (2012).

9. K.K.B. Hon, L. Li, and I.M. Hutchings, CIRP Ann. Manuf. Technol. 57, 601 (2008).

10. N. Travitzky, A. Bonet, B. Dermeik, B. Dermeik, T. Fey, I. Filbert-Demut, T. Schlier, and P. Schlordt, Adv. Eng. Mater. 16, 729 (2014).

11. J.J. Lewandowski and M. Seifi, Annu. Rev. Mater. Res. 46, $151(2016)$

12. D. Herzog, V. Seyda, E. Wycisk, and C. Emmelamnn, Acta Mater. 117, 371 (2016).

13. L.E. Murr, S.M. Gaytan, D.A. Ramirez, E. Martinez, J. Hernandez, K.N. Amato, P.W. Shindo, F.R. Medina, and R.B. Wicker, J. Mater. Sci. Technol. 28, 1 (2012).

14. M. Zietala, T. Durejko, M. Polanski, I. Kunce, T. Plocinski, W. Zielinski, M. Lazinska, W. Stepniowki, T. Czujko, K.J. Kurzdlowski, and Z. Bojar, Mater. Sci. Eng. A 677, 1 (2016).

15. W.J. Sames, F.A. List, S. Pannala, R.R. Dehoff, and S.S. Babu, Int. Mater. Rev. 61, 315 (2016).

16. P. Ganesh, R. Giri, R. Kaul, P. Sankar, P. Tiwari, A. Atulkar, R.K. Porwal, R.K. Dayal, and L.M. Kukreja, Mater. Des. 39, 509 (2012).

17. I.A. Segura, J. Mireles, D. Bermudez, C.A. Terrazas, L.E. Murr, K. Li, V.S.Y. Injeti, R.D.K. Misra, and R.B. Wicker, J. Nucl. Mater. 507, 164 (2018).

18. S.-X. Li, L. Li, S.-R. Yu, R. Akid, and H.-B. Xia, Corros. Sci. 53, 99 (2011).

19. J.A. Sedriks, Corrosion of Stainless Steels, $2^{\text {nd }}$ ed., (WileyInterscience, New York, 1996), pp. 13-74, 231-262.

20. S.M. Brummer, L.A. Charlot, and D.G. Alteridge, Report NUREG/CR-3918, PML-5186 (Richland: Pacific Northwest Laboratory, 1984).

21. J.R. Davis, Chapter 1: Basic Understanding of Weld Corrosion, Corrosion of Weldments (Materials Park: ASM International, 2006), pp. 1-12.

22. P.I. Marshall and T.G. Gooch, Corrosion (Houston, TX, U. S.), 6, 514 (1993).

23. W. Jiang, Y. Zhang, and W. Woo, Int. J. Pressure Vessels Piping 92, 56 (2012).

24. H. Shaikh, B.P.C. Rao, R.P. Gupta, R.P. George, S. Venugopal, B. Sasi, T. Jayakumar, and H.S. Khatak, Br. Corros. J. 37, 129 (2002)

25. S. Kou, Welding Metallurgy, 2nd ed., (Wiley, New Jersey, 2003), pp. 145-170, 199-213, 243-261, 431-452.
26. G.F. Dinda, A.K. Dasgupta, and J. Majumder, Mat. Sci. Eng. A 509, 98 (2009).

27. F.-J. Kahlen and A. Kar, J. Laser Appl. 13, 60 (2001).

28. C. García, F. Martín, P. de Tiedra, Y. Blanco, J.M. RuízRoman, and M. Aparicio, Corr. Sci. 50, 687 (2008).

29. C. García, F. Martín, P. de Tiedra, and L.G. Cambronero, Corr. Sci. 49, 1718 (2007).

30. W. Meiners, K. Wissenbach, R. Poprawe, and D. Gu, Int. Mat. Rev. 57, 133 (2012).

31. V. Cihal, Corr. Sci. 20, 737 (1980).

32. P. Novak, R. Stefec, and F. Franz, Corrosion 31, 344 (1975).

33. W.L.C., Romero and W.M., Danko, J.C. Report GEAP21382, ID: 7299900, GEC, California, (1976).

34. H. Shaikh, N. Sivaibharasi, B. Sasi, T. Anita, B.P.C. Rao Kumar, R. Dayla, T. Jayakumar, and B. Raj, Weld. World 56, 44-54 (2012).

35. P. Ahmedabadi, V. Kain, R.P. Singh, and P.K. De, J. Mater. Eng. Perform. 12, 529-536 (2003).

36. G.T. Gray, V. Livescu, P.A. Rigg, C.P. Trujillo, C.M. Cady, S.R. Chen, J.S. Carpenter, T.J. Lienert, and S.J. Fensin, Acta Mater. 138, 140 (2017).

37. B.M. Morrow, T.J. Lienert, C.M. Knapp, J.O. Sutton, M.J. Brand, R.M. Pacheco, V. Livescu, J.S. Carpenter, and G.T. Gray III, Metall. Mater. Trans. A 49A, 3637 (2018).

38. J.R. Trelewicz, G.P. Halada, O.K. Donaldson, and G. Manogharan, JOM 68, 850 (2016).

39. ASTM standard A276/A276 M-17, Standard Specification for Stainless Steel Bars and Shapes, ASTM Book of Standards, American Society for Testing of Metals, (2017).

40. ASTM standard G108-94, "Standard Test Method for Electrochemical Reactivation (EPR) for Detecting Sensitization of AISI Types 304 and 304L Stainless Steels", ASTM Book of Standards, American Society for Testing of Metals, Philadephia PA (2015)

41. W.L. Clarke, R.L. Cowan, and W.L. Walker, Intergranular corrosion of stainless alloys, (ASTM STP 656, R. F. Steigrwald, Ed., American Society for Testing and Materials, (1978)) pp. 99-132.

42. P.D. Teidra, Ó. Martín, M. López, and M. San-Juan, Corr. Sci. 53, 1563 (2011)

43. G.H. Aydoğdu and M.K. Aydinol, Corr. Sci. 48, 3565 (2006).

44. H. Sidhom, T. Amadou, H. Sahlaoui, and C. Braham, Metall. Mater. Trans. A 38A, 1269 (2007).

45. B. Weiss and R. Stickler, Metall. Trans. 3, 851 (1972).

46. P. Záhumenský, S. Tuleja, S. Tuleja, J. Országová, J. Janovec, and V. Siládiová, Corr. Sci. 41, 1305 (1999).

47. D.N. Wasnik, V. Kain, I. Samajdar, B. Verlinden, and P.K. De, Acta Mater. 50, 4587 (2002).

48. A. Kriaa, N. Hamdi, and H. Sidhom, Prot. Met. Phys. Chem. 44, 506 (2008).

49. R. Annamalai, A. Upadhyaya, and D.K. Agrawal, Can. Metall. Q. 54, 142 (2015).

50. S.S. Panda, V. Singh, A. Upadhyaya, and D. Agrawal, Scripta Mater. 54, 2179 (2016).

51. G.H. Lei, R.M. German, and H.S. Nayar, Powder Metall. Int. 15,70 (1983)

52. M.C. Baran and B.A. Shaw, Int. J. Powder Metall. 36, 57 (2000).

53. T.G. Gooch, Weld. Res., 135 (1996) 